\title{
PRADER-WILLI SYNDROME (PWS)
}

\author{
Hamid $\mathrm{S}^{1}$, Islam $\mathrm{MS}^{2}$, Chowdhury $\mathrm{ZI}^{3}$
}

\begin{abstract}
An eleven-year-old boy reported with increasing body weight and appetite since birth. He is suffering from insulin dependent diabetes since ten years of age and underwent extensive investigation including MRI of brain. His physical findings, biochemical and MRI findings were consistent with Prader-Willi syndrome (PWS).
\end{abstract}

\section{Introduction}

Prader-Willi syndrome (PWS) is a disorder caused by a deletion or disruption of genes in the proximal arm of chromosome 15 or by maternal disomy in the proximal arm of chromosome 15. In many patients without a detectable cytogenic abnormality, FISH (Florescent in situ hybridization) analysis revealed smaller deletion within the same region. It is striking that in all cases the deletion affects the paternally derived chromosome. The genetic basis of PWS is complex ${ }^{1-4}$.

Characteristics of the syndrome include developmental delay, poor muscle tone, short stature, small hands and feet, incomplete sexual development and unique facial features. Insatiable appetite is a classic feature of PWS. This uncontrollable appetite can lead to health problems and behavior disturbances ${ }^{5}$.

\section{Case report}

An eleven-year-old boy presented with the complaints of increasing body weight and appetite since birth. His body weight was about $42 \mathrm{~kg}$. He was bulky and over weight in relation to his height and age. He was unable to talk in clear articulation. He talks in blurring word. Physical examination reveals puffy appearance of face with short webby neck, raised buttock with excessive fat deposition in the thigh and protruded belly. There was excess fat deposition, especially in the central portion of the body.

Eyes were small, hyper telluric and almond shaped. The boy was with thin, down-turned lips, prominent nasal bridge, high and narrow forehead, easily bruised soft skin (Fig-1). He was picking at his skin. Stria were present on surface of skin in the lower abdomen and loin. Frenulum of his tongue was short. Limbs were short asymmetric. Right lower limb was longer than left; that he tried to compensate by standing on his left leg (Fig-2) and keeping his right leg in some degree of flexed. Fingers and toes were slightly short in length.

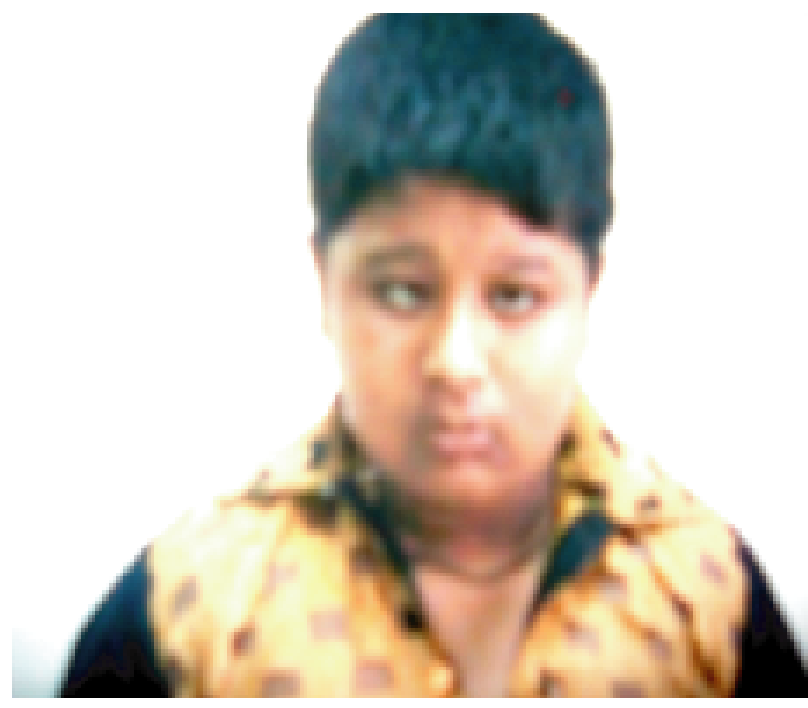

Fig-1: Small, hyper tellurium, almond shaped eyes with thin, down-turned lips, prominent nasal bridge and high narrow forehead.

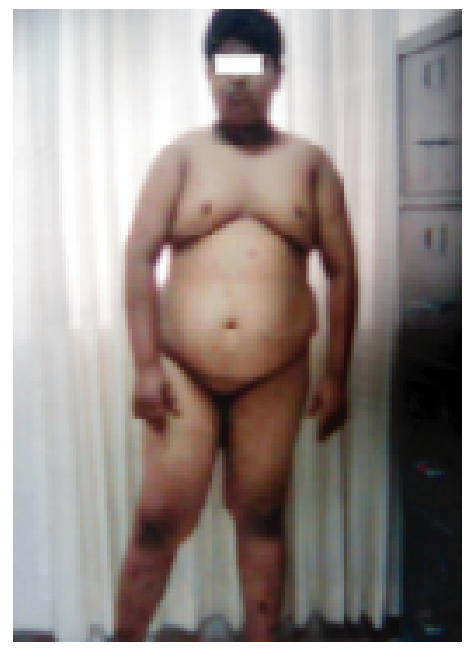

Fig-2: Short asymmetric limbs with longer right lower limb.

His external genital organ (penis) was small (rudimentary). Testes were so small that in palpation that

1. Dr Shaheda Hamid MBBS, MPH, Medical Officer, NIPSOM, Dhaka; 2. Col Md Saiful Islam MBBS, FCPS, Classified Specialist in Radiology, CMH Chittagong; 3. Brig Gen Zuberul Islam Chowdhury MBBS, FCPS; Former-Professor of Radiology, AFMC. 
was felt like thin cord. He had sparsely distributed pubic hairs and lack of complete sexual development. Muscles were thin and hypotonic. Learning disabilities / borderline intellectual functioning was noted. MRI of the brain revealed small pituitary fossa, small mandible, mild ventriculomegaly and small polyp in the left maxillary sinus. $\mathrm{X}$ ray of the hand and pelvis correspond with the chronological age of the patient. Blood picture was within normal limits except mild anaemia and mild hyperglycemia.

\section{Discussion}

The first patient with features of PWS was described by Dr Prader, Dr Willi and Dr. Lambert in 1956. Since that time, the complex genetic basis of PWS has begun to be understood. Initially, scientists found that individuals with PWS have a portion of genetic material deleted (erased) from chromosome 15. In order to have PWS, the genetic material must be deleted from the chromosome 15 received from one's father. If the deletion is on the chromosome 15 inherited from one's mother, a different syndrome develops. This was an important discovery, for it demonstrated for the first time that the genes inherited from one's mother can be expressed differently than the genes inherited from one's father. It is striking that in all cases the deletion affects the paternally derived chromosome $15^{4,5}$.

Newborns with PWS generally have poor muscle tone, (hypotonia) and do not feed well. This can lead to poor weight gain and failure to thrive. Genitalia can be smaller than normal, and a male with PWS may have undescended testicles. Hands and feet are also typically smaller than normal. Some patients with PWS have unique and subtle facial characteristics that are detectable only by physicians. Cassidy found that $40 \%$ of individuals with PWS have borderline/low average intelligence, a figure higher than that found in Curfs and Frym's study $32 \%{ }^{7}$. However, both studies suggest that most individuals $(50-65 \%)$ fall within the mild/borderline/low average intelligence range. Hypothalamus regulates many basic processes, including appetite, there may well be a link. However, no organic defect of the hypothalamus was found on post mortem investigation $^{8}$.

As children with PWS age, development is typically slower than normal. Developmental milestones, such as crawling, walking and talking occur later than usual. Developmental delay continues into adulthood for approximately $50 \%$ of individuals with PWS. At about one to two years of age, children with PWS develop an uncontrollable, insatiable appetite. These children, if not controlled, will eat until they suffer from life-threatening obesity, including respiratory failure with hypoxia (low blood oxygen levels), cor-pulmonale (right-sided heart failure), and death. The desire to eat can also lead to significant behavior problems but does not develop organic defect of the hypothalamus ${ }^{8}$.

Auditory information processing and sequential processing are relatively poor, as are arithmetic and writing skills, visual and auditory short term memory and auditory attention span. These sometimes improve with age, but deficits in these areas remain throughout adulthood $^{4}$. Children with PWS show an unusual cognitive profile. They are often strong in visual organization and perception, including reading and vocabulary, but their spoken language (sometimes affected by hyper nasality) is generally poorer than their comprehension. A marked skill in completing jigsaw puzzles has been noted ${ }^{5,9}$. PWS affects approximately 1 in 10,000 to 25,000 live births. It is the most common genetic cause of life-threatening obesity. It affects both males and females. PWS can be seen in all races and ethnic groups.

\section{Conclusion}

Prader-Willi syndrome (PWS) is a genetic condition requiring lifelong support and care. If food intake is strictly monitored and various therapies provided, individuals with PWS have a normal life expectancy.

\section{Refernces}

1. Butler, Merlin G, Thompson T. Prader-Willi Syndrome: Clinical and Genetic Findings. The Endocrinologist 2000;10: 3s-16s.

2. Hawkey CJ, Smithies A. The Prader-Willi syndrome with a 15/15 translocation. Case report and review of the literature. J Med Genet 1976;13:152-157

3. Ann Scheimann. Prader-Willi Syndrome. eMedicine; Updated: Jul 27, 2009.

Available at: http://emedicine.medscape.com/article/947954-overview 4. Runte M, Varon R, Horn D, Horsthemke B, Buiting K. Exclusion of the C/D box snoRNA gene cluster HBII-52 from a major role in Prader-Willi syndrome. Hum Genet. 2005 Feb;116(3):228-30.

5. Cassidy SB, Driscoll DJ. Prader-Willi syndrome. European Journal of Human Genetics 2009; 17: 3-13.

5. Kumar V, Abbas AK, Fausto N. Robbins and Cotran Pathologic Basis of Disease. 7th ed. India: Thomson Press Ltd; 2006. p. 186-187.

7. Curfs LMG, Fryns JP. Prader-Willi syndrome: a review with special attention to the cognitive and behavioral profile. Birth Defects 1992; 28:99-104

8. Cassidy SB. Prader Willi Syndrome. Journal of Medical Genetics 1997; 34: 917-23.

9. Holm VA, Cassidy SB, Butler MG, Hanchett JM, Greenswag LR, Whitman BY, Greenberg F. Prader-Willi syndrome: Consensus diagnostic criteria. Pediatrics 1993; 91(2): 398-402 